\title{
BRADYKININ OR ACETYLCHOLINE AS VASODILATORS TO TEST ENDOTHELIAL VENOUS FUNCTION IN HEALTHY SUBJECTS
}

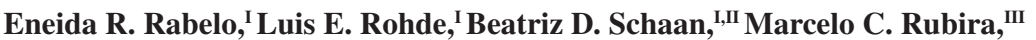 \\ Karen B. Ruschel, ${ }^{I}$ Rodrigo D. M. Plentz, ${ }^{\mathrm{I}, \mathrm{IV}}$ Fernanda M. Consolim-Colombo, ${ }^{\mathrm{II}}$ \\ Maria Cláudia Irigoyen, ${ }^{\mathrm{I}, \mathrm{II}, \mathrm{III}}$ Heitor Moreno JuniorV
}

doi: 10.1590/S1807-59322008000500017

Rabelo ER, Rohde LE, Schaan BD, Rubira MC, Ruschel KB, Plentz RDM et al. Bradykinin or acetylcholine as vasodilators to test endothelial venous function in healthy subjects. Clinics. 2008;63(4):677-82.

INTRODUCTION: The evaluation of endothelial function has been performed in the arterial bed, but recently evaluation within the venous system has also been explored. Endothelial function studies employ different drugs that act as endothelium-dependent vasodilatory response inductors.

OBJECTIVES: The aim of this study is to compare the endothelium-dependent venous vasodilator response mediated by either acetylcholine or bradykinin in healthy volunteers.

METHODS AND RESULTS: Changes in vein diameter after phenylephrine-induced venoconstriction were measured to compare venodilation induced by acetylcholine or bradykinin (linear variable differential transformer dorsal hand vein technique). We studied 23 healthy volunteers; $31 \%$ were male, and the subject had a mean age of $33 \pm 8$ years and a mean body mass index of $23 \pm 2 \mathrm{~kg} /$ $\mathrm{m}^{2}$. The maximum endothelium-dependent venodilation was similar for both drugs $(\mathrm{p}=0.13)$, as well as the mean responses for each dose of both drugs $(\mathrm{r}=0.96)$. The maximum responses to acetylcholine and bradykinin also had good agreement.

CONCLUSION: There were no differences between acetylcholine and bradykinin as venodilators in this endothelial venous function investigation.

KEYWORDS: Endothelium; Vascular; Veins; Acetylcholine; Bradykinin.

\section{INTRODUCTION}

Evaluation of endothelial function has been investigated in recent years using different approaches, and these results have contributed significantly to the understanding of its importance in physiological and pathological

\footnotetext{
${ }^{\text {I }}$ Universidade Federal do Rio Grande do Sul - Porto Alegre/RS, Brazil. II Instituto de Cardiologia do Rio Grande do Sul / Fundação Universitária de Cardiologia - Porto Alegre/RS, Brazil.

III Instituto do Coração (InCor), Universidade de São Paulo - São Paulo/ SP, Brazil.

${ }^{\text {IV }}$ Universidade Federal de Ciências da Saúde de Porto Alegre (UFCSPA) Porto Alegre/RS, Brazil.

v Departamento de Farmacologia, Universidade de Campinas (Unicamp) Campinas/SP, Brazil.

Phone: 55512101.8843

Email: rabelo@portoweb.com.br

Received for publication on June 26, 2008

Accepted for publication on July 29, 2008
}

conditions. ${ }^{1-3}$ Endothelial dysfunction is frequently present in common chronic degenerative disorders, such as diabetes, hypertension and coronary artery disease. ${ }^{4}$ Thus, its detection may assist in the prevention and early treatment of these diseases.

Although traditionally the evaluation of endothelial function has been performed in the arterial bed, recently the evaluation of the venous system has been explored under diverse conditions. ${ }^{5-7}$ The venous system contains $70 \%$ of the blood volume, which is mainly present in small veins. ${ }^{8}$ Arteries and veins have different biological activities in terms of the endothelium; this is most likely due to marked regional and segmental heterogeneity in vascular endothelial function. ${ }^{6}$ Veins are extremely important under specific conditions, such as hypertension, heart failure, and other cardiovascular disorders. ${ }^{5,7-9}$ Studies on arterial and venous endothelial function usually employ drugs that act 
as inductors of the endothelium-dependent vasodilatory response. ${ }^{10}$ The endothelium-dependent vasodilatory response may be elicited by infusion of substances that promote the synthesis or liberation of nitric oxide (NO) by the endothelium. Bradykinin, for example, is produced from its substrate, kininogen, by the action of kallikrein. Endothelial cells express, in a constitutive manner, B2 kinin receptors, which are activated by, among other substances, bradykinin. Agonism of these receptors activates phospholipase c, mobilizing the entrance of intracellular calcium, which stimulates NO synthesis. Thus, the end effect of the bradykinin action is to enhance endotheliumdependent vasodilatation through the liberation of NO. ${ }^{11}$ As bradykinin effects are predominantly local in the evaluation of the venous endothelium, several studies have utilized the infusion of this substance to induce an endotheliumdependent response. ${ }^{6,12,13}$

Because of the way in which the vasomotor response to acetylcholine or other agonists of the muscarinic receptors are evaluated, several studies have also utilized regional infusions of this substance, usually intra-arterial, to measure endothelium-dependent vasodilation. ${ }^{2,14,15}$ The use of acetylcholine in this context has potential advantages: the simplicity of its use, its favorable cost and its well-known effects on the arterial endothelium. However, studies performed in the late 1980s that utilized acetylcholine as an endothelium-dependent vasodilator agent demonstrated that high-dose infusions of acetylcholine caused a vasoconstrictor effect in the venous endothelium. ${ }^{9,16}$ One of these studies demonstrated that only low-dose acetylcholine infusions produced vasodilation. ${ }^{16}$

Faced with these findings, in this study we intend to perform, in healthy volunteers, a comparative analysis of the endothelium-dependent venous vasodilator response mediated by acetylcholine vs. bradykinin.

\section{METHODS}

\section{Subjects}

The study was carried out in 23 healthy volunteers, $31 \%$ male, with a mean age of $33 \pm 8$ years (range 20 to 45 ) and a mean body mass index of $23 \pm 2 \mathrm{~kg} / \mathrm{m}^{2}$. All were healthy, as determined by a complete physical examination and routine laboratory tests (fasting glycemia, lipids, full blood count). Exclusion criteria were a personal history of diabetes, hypertension, and any vascular disease, drug abuse, alcoholism, smoking or chronic use of any medication. Each subject gave written informed consent to participate in this study, which was approved by the ethical committee of our institution.

\section{Dorsal Hand Vein Technique}

The dorsal hand vein technique, previously modified by Aellig, ${ }^{17}$ was used to measure the responsiveness of the dorsal hand vein to acetylcholine, bradykinin and sodium nitroprusside in the hand vein pre-constricted using phenylephrine. In each experimental session, we allowed a 20 min interval between infusions of both acetylcholine and sodium nitroprusside, and bradykinin and sodium nitroprusside. The subjects were studied in the supine position with one arm placed on a padded support with an upward angle of 30 degrees from the horizontal position to ensure complete emptying of the superficial hand veins. A suitable vein was chosen on the dorsum of the hand, and a 23-gauge needle was inserted. A tripod holding a linear variable differential transformer (Shaevitz Engineering, NJ) was mounted on the back of the hand, with the central aperture of the linear variable differential transformer, containing a movable metal core, at a distance of $10 \mathrm{~mm}$ downstream from the tip of the needle. The signal output of the linear variable differential transformer, which is linearly proportional to the vertical of the core, gives a measurement of the diameter of the vein. Readings were made under a congestive pressure of $40 \mathrm{mmHg}$ by inflating a blood pressure cuff placed on the upper portion of the arm under study. Normal saline solution was infused for at least 30 min to allow for equilibration of the veins after the initial vasoconstriction due to needle insertion. This baseline vasodilation during saline infusion with the cuff inflated was defined as $100 \%$ relaxation; the recording obtained with the cuff not inflated (and the vein emptied) was defined as $100 \%$ constriction. The difference between the two positions of the core gave a measure of the diameter changes of the vein under congestive pressure. All local drug infusions lasted for at least $3 \mathrm{~min}$. At the end of this time, the cuff was inflated up to the maximum response or by a 3-min period, even if no response was obtained. Subsequently, the cuff was deflated. Increasing concentrations of a drug were infused in a sequential manner.

Phenylephrine, an -adrenoceptor-selective agonist, was used to produce vasoconstriction of the hand vein. A doseresponse curve to phenylephrine was performed in each subject with a dose range of 0.06 to $8 \mathrm{nmol} / \mathrm{min}$. In this way, the dose of phenylephrine that produced $80 \%$ of maximal venous constriction was determined and was kept constant during the entire study, and this degree of constriction was defined as $0 \%$ dilatation for the purpose of subsequent calculations. We allowed a 20-min interval between infusions of agonists. Since acetylcholine and bradykinin are rapidly degraded and each dose was only injected after complete recovery (approximately $2 \mathrm{~min}$ ) of venous tone to 
baseline, baseline conditions were re-established between the drug injections and between the different agonists. Preliminary experiments indicated that phenylephrineinduced venoconstriction was stable during this period. ${ }^{18}$

The vasodilator response in this study was calculated as a percentage in the range of 0 to $100 \%$ dilation. Drugs were infused using a Harvard infusion pump (Harvard Apparatus, South Natick, MA) at a flow rate of $0.3 \mathrm{ml} / \mathrm{min}$. Blood pressure and heart rate were monitored in the opposite arm during the experiment. All experiments were performed in a temperature-controlled laboratory $\left(26-28^{\circ} \mathrm{C}\right)$.

Endothelium-dependent venodilation was tested by infusing five increasing doses $(0.02-20 \mathrm{nmol} / \mathrm{min})$ of acetylcholine (Sao Paulo University, Pharmacy Division, Sao Paulo, Brazil) and five increasing doses (1-260 pmol/min) of bradykinin (Clinalfa). Endothelium-independent venodilation was tested by infusing three increasing doses $(2-7 \mathrm{nmol} / \mathrm{min})$ of sodium nitroprusside (Biolab Sanus Pharmacy Ltda, Sao Paulo, Brazil).

\section{Data analysis}

The variables are reported as mean \pm standard deviation. Comparisons between continuous variables were performed using the Student $t$-test or Wilcoxon test for nonparametric values, and those between categorical variables were made using the $\chi^{2}$ test for trend. The relationship between endothelial function and clinical variables was evaluated by calculating the Pearson correlation coefficient. Values of $\mathrm{p}$ $<0.05$ were considered to be statistically significant. This analysis was performed with the statistics software SAS 6.0 for Windows.

\section{RESULTS}

Clinical characteristics of the studied subjects were as follows: the subjects were on average 33 years-old, $31 \%$ were male, they had normal weight and body mass index, and they also had normal blood pressure levels and plasma lipids and glucose, as expected (Table 1).

Acetylcholine, bradykinin, phenylephrine and sodium nitroprusside infusions were well tolerated. None of the pharmacological intervention procedures resulted in changes in the blood pressure or heart rate, indicating that the doses used had no systemic effect, as expected. The maximum endothelium-dependent venodilation responses obtained by administering acetylcholine or bradykinin were that acetylcholine elicited an endothelium-dependent venodilation of $88 \pm 38 \%$, while bradykinin causes a $105 \pm$ $41 \%$ venodilation $(\mathrm{p}=0.12)$, as compared to basal values (Figure 1).
Table 1 - Characteristics of the studied subjects

\begin{tabular}{lc}
\hline Characteristic & Mean \pm SD or $\mathrm{n}(\%)$ \\
\hline Age (years) & $33 \pm 8$ \\
Gender (male) & $7(30 \%)$ \\
Race (Caucasian) & $23(100 \%)$ \\
Weight (kg) & $65 \pm 9$ \\
Height (m) & $1.69 \pm 0.08$ \\
BMI (Kg/m $\left.{ }^{2}\right)$ & $22.8 \pm 2.3$ \\
SBP (mmHg) & $113 \pm 13$ \\
DBP (mmHg) & $73 \pm 7$ \\
PP (mmHg) & $38 \pm 8$ \\
HR (bpm) & $72 \pm 7$ \\
Glycemia (mg/dL) & $87 \pm 8$ \\
Total cholesterol (mg/dL) & $190 \pm 37$ \\
Triglycerides (mg/dL) & $91 \pm 46$ \\
HDL-c (mg/dL) & $63 \pm 14$ \\
Hematocrit (\%) & $40 \pm 3$ \\
\hline
\end{tabular}

The values are reported as mean \pm standard deviation or percentages. BMI: Body mass index; SBP: Systolic blood pressure; DBP: diastolic blood pressure; PP: Pulse pressure; HR: Heart rate; HDL-c: High-density lipoprotein cholesterol.

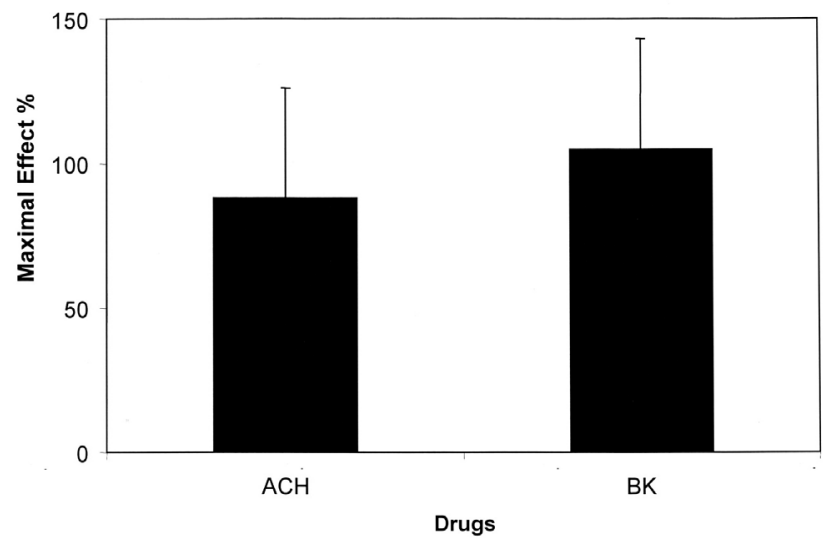

Figure 1 - Percentage maximal response from baseline (maximal effect, \%) after infusion of acetylcholine ( $\mathrm{ACH})$ and bradykinin $(\mathrm{BK})$

The numerical values for acetylcholine and bradykinin responses, at each dose tested, are represented in Figure 2 and are also given at the bottom of the figure. The mean venodilation induced by 0.02 to $20 \mathrm{nmol} / \mathrm{min}$ of acetylcholine and 1 to $260 \mathrm{pmol} / \mathrm{min}$ of bradykinin were similar. The data suggest a similar initial behavior of dose-dependent vasodilation, with dependent and linear characteristics for both infusions.

We also performed a correlation by plotting the percentage vasodilation observed with each dose of acetylcholine vs. the percentage vasodilation observed with 


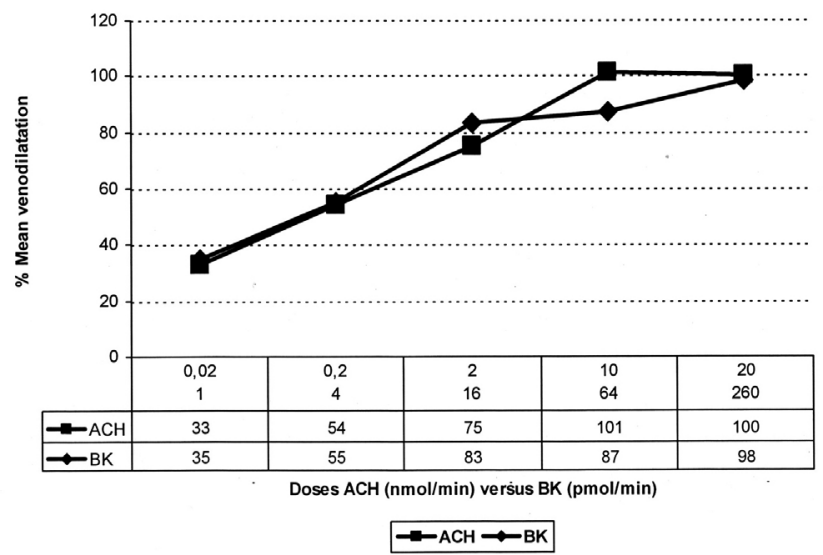

Figure 2 - Relationship between venodilation responses (\% mean venodilation) for each dose of acetylcholine (ACH) or bradykinin (BK) infusion

each dose of bradykinin; there was good agreement between the responses for each drug $(r=0.96, p=0.007)$.

\section{DISCUSSION}

The most important finding of the present study was the demonstration that acetylcholine, administered in low-tomoderate concentrations, may be used as a tool to analyze endothelium-dependent venodilation using the dorsal hand vein technique. This finding is based on the direct comparison of data obtained with bradykinin in the same subjects.

The first study ${ }^{19}$ involving venous endothelium reported a dose-dependent dilator effect of acetylcholine on preconstricted superficial hand veins, an effect that could be blocked by the local infusion of atropine. Removal of the endothelium of the vein by local irrigation with distilled water abolished the acetylcholine venodilator effect, which could therefore be ascribed to the effect of locally-released NO. ${ }^{20}$ Studies carried out by Vallance et al. also showed that the venodilation produced by acetylcholine is mediated via endothelium NO release. ${ }^{9}$ However, in veins with an intact endothelium, the dose-response relationship for acetylcholine was found to be biphasic; low doses produce venodilation, and high doses produce venoconstriction. In light of these results, other authors questioned the use of this drug in dose-response curves as an endothelial function evaluation. ${ }^{16}$ Bradykinin has been used to evaluate endothelium-dependent venodilation because of the possibility of constructing a dose-effect curve. . $, 6,12,21^{2}$

In the present study, we compared the endotheliumdependent venodilation response produced by acetylcholine and bradykinin in healthy individuals. We observed that the maximum mean responses produced by acetylcholine and bradykinin were similar in healthy individuals. In their classic study, Collier et al. showed that the maximum response produced by acetylcholine was $28 \%$ at a dose of 1 $\mathrm{nmol} / \mathrm{min} ; 10 \mathrm{nmol} / \mathrm{min}$ did not produce venodilation and $100 \mathrm{nmol} / \mathrm{min}$ produced venoconstriction. ${ }^{16}$ Furthermore, the authors demonstrated that the venodilation was endothelium-dependent, since the response was abolished after endothelium removal. In the present study, we evaluated the dorsal hand vein response in 23 healthy individuals, and the doses of acetylcholine were 0.02 to $20 \mathrm{nmol} / \mathrm{min}$ (5 doses). The maximum venodilatory response was $88 \pm 38 \%$, as compared to the 5 doses of bradykinin usually employed that caused a maximum response of $105 \pm 41 \%$. The difference between the two substances was mainly due to the concentration of the acetylcholine doses. It is important to note that we did not find evidence of desensitization during acetylcholine dose-response curves.

Many hypotheses have been proposed to explain the variability of maximum venodilation during acetylcholineinfusion, which may be derived from the functional endothelium or the vascular smooth muscle. ${ }^{22}$ Indeed, the use of this technique has been well accepted in the literature, but some variability is expected, as demonstrated by previous studies..$^{22,23}$ Concerning other factors that might contribute to the heterogeneous venodilatory responses to acetylcholine, Grossmann et al. tested if the variable responses to acetylcholine in healthy subjects could be associated with two polymorphisms for proteins involved in the signal transduction pathway (the G-protein beta-3 subunit GNB3) and endothelial nitric oxide synthase, (eNOS). They concluded that the variable venous responses to acetylcholine in humans were not related to acetylcholine esterase activity, GNB3 or the eNOS gene variant. ${ }^{23}$ Finally, tachyphilaxis, a process characterized by a gradual reduction in the number of receptors or a change in their conformation, inhibiting the adequate link between the agonist under its continued exposition to the receptor, could not be excluded. However, this mechanism was not explored in the present study.

Similar responses to acetylcholine and bradykinin at different doses were observed upon comparison. However, the pattern of venodilation produced by bradykinin was similar to that of acetylcholine, which might be explained by the multiple mechanisms involved in this process; the stimulation of the $\mathrm{B} 2$ receptors causes liberation of prostacyclin, $\mathrm{NO}$ and a hyperpolarizing factor derived from the endothelium. ${ }^{24}$ It is believed that vasodilation mediated by acetylcholine occurs only via NO. ${ }^{20}$

The performance of acetylcholine as compared to bradykinin in inducing endothelium venous vasodilatory was evaluated considering several aspects. The relationship between venodilation response for each dose of infused acetylcholine and bradykinin showed that the drugs had 
equivalent actions, implying that they are both efficient in venous endothelium evaluation. There is evidence in humans that both drugs have a similar vasomotor response pattern in coronary arteries, ${ }^{25}$ which reinforces the idea that the utilization of acetylcholine as a vasodilatory stimulus is comparable to bradykinin in the venous endothelium.
In conclusion, there were no differences between acetylcholine and bradykinin as they were used as venodilators in this endothelial venous function investigation. Both drugs may be safely used for the evaluation of endothelial venous function. This fact is very important, since acethylcholine is cheaper than bradykinin.

\section{REFERENCES}

1 Corretti MC, Anderson TJ, Benjamin EJ, Celermajer D, Charbonneau F, Creager MA, et al. Guidelines for the ultrasound assessment of endothelial-dependent flow-mediated vasodilation of the brachial artery: a report of the International Brachial Artery Reactivity Task Force. J Am Coll Cardiol. 2002;39:257-65.

2 Fang JC, Kinlay S, Beltrame J, Hikiti H, Wainstein M, Behrendt D, et al. Effect of vitamins $\mathrm{C}$ and $\mathrm{E}$ on progression of transplant-associated arteriosclerosis: a randomised trial. Lancet. 2002;359:1108-13.

3 Playford DA, Watts GF. Special article: non-invasive measurement of endothelial function. Clin Exp Pharmacol Physiol. 1998;25:640-3.

4 Brunner H, Cockcroft JR, Deanfield J, Donald A, Ferrannini E, Halcox J, et al. Endothelial function and dysfunction. Part II: Association with cardiovascular risk factors and diseases. A statement by the Working Group on Endothelins and Endothelial Factors of the European Society of Hypertension. J Hypertens. 2005;23:233-46.

5 Bedarida GV, Bushell E, Haefeli WE, Blaschke TF, Hoffman BB. Responsiveness to bradykinin in veins of hypercholesterolemic humans. Circulation. 1993;88:2754-61.

6 de Sousa MG, Yugar-Toledo JC, Rubira M, Ferreira-Melo SE, Plentz $\mathrm{R}$, Barbieri D, et al. Ascorbic acid improves impaired venous and arterial endothelium-dependent dilation in smokers. Acta Pharmacol Sin. $2005 ; 26: 447-52$

7 Rubira MC, Consolim-Colombo FM, Rabelo ER, Yugar-Toledo JC, Casarini D, Coimbra SR, et al. Venous or arterial endothelium evaluation for early cardiovascular dysfunction in hypertensive patients? J Clin Hypertens (Greenwich). 2007;9:859-65.
8 Blochl-Daum B, Vierhapper H, Eichler HG, Waldhausl W. Endothelininduced venoconstriction is unaffected by type 2-diabetes: in vivo effect of histamine on the endothelin action on veins. Arch Int Pharmacodyn Ther. 1992;316:90-6.

9 Vallance P, Collier J, Moncada S. Nitric oxide synthesised from L-arginine mediates endothelium dependent dilatation in human veins in vivo. Cardiovasc Res. 1989;23:1053-7.

10 Haas E, Meyer MR, Schurr U, Bhattacharya I, Minotti R, Nguyen HH, et al. Differential effects of 17 beta-estradiol on function and expression of estrogen receptor alpha, estrogen receptor beta, and GPR30 in arteries and veins of patients with atherosclerosis. Hypertension. 2007;49:135863.

11 Dachman WD, Ford GA, Blaschke TF, Hoffman BB. Mechanism of bradykinin-induced venodilation in humans. J Cardiovasc Pharmacol. 1993;21:241-8.

12 Chalon S, Moreno H, Jr., Benowitz NL, Hoffman BB, Blaschke TF Nicotine impairs endothelium-dependent dilatation in human veins in vivo. Clin Pharmacol Ther. 2000;67:391-7.

13 Chalon S, Moreno H, Jr., Hoffman BB, Blaschke TF. Angiotensinconverting enzyme inhibition improves venous endothelial dysfunction in chronic smokers. Clin Pharmacol Ther. 1999;65:295-303.

14 Giribela CR, Rubira MC, de Melo NR, Plentz RD, de Angelis K, Moreno $\mathrm{H}$, et al. Effect of a low-dose oral contraceptive on venous endothelial function in healthy young women: preliminary results. Clinics. 2007;62:151-8 
15 Stepniakowski KT, Lu G, Miller GD, Egan BM. Fatty acids, no insulin, modulate alpha1-adrenergic reactivity in dorsal hand veins. Hypertension. 1997;30:1150-5.

16 Collier J, Vallance P. Biphasic response to acetylcholine in human veins in vivo: the role of the endothelium. Clin Sci. 1990;78:101-4.

17 Aellig WH. A new technique for recording compliance of human hand veins. Br J Clin Pharmacol. 1981;11:237-43.

18 Schindler C, Grossmann M, Dobrev D, Francke K, Ravens U, Kirch W. Reproducibility of dorsal hand vein responses to phenylephrine and prostaglandin F2 alpha using the dorsal hand vein compliance method. J Clin Pharmacol. 2003;43:228-36.

19 Collier JG, Nachev C, Robinson BF. Effect of catecholamines and other vasoactive substances on superficial hand veins in man. Clin Sci. 1972;43:455-67.

20 Collier J, Vallance, P. Endothelium-derived relaxing factor is an endogenous vasodilator in man. Br J Pharmacol. 1989;97:639-41.
21 Dachman WD, Ford GA, Hoffman BB, Blaschke TF. Bradykinininduced venodilation is not impaired with aging in humans. J Gerontol. 1992;47:M166-70.

22 Furchgott RF. Role of endothelium in responses of vascular smooth muscle. Circ Res. 1983;53:557-73.

23 Grossmann M, Dobrev D, Siffert W, Kirch W. Heterogeneity in hand veins responses to acetylcholine is not associated with polymorphisms in the G-protein beta3-subunit (C825T) and endothelial nitric oxide synthase (G894T) genes but with serum low density lipoprotein cholesterol. Pharmacogenetics. 2001;11:307-16.

24 Hornig B, Drexler H. Endothelial function and bradykinin in humans. Drugs. 1997;54 Suppl 5:42-7.

25 Kato M, Shiode N, Yamagata T, Matsuura H, Kajiyama G. Coronary segmental responses to acetylcholine and bradykinin in patients with atherosclerotic risk factors. Am J Cardiol. 1997;80:751-5. 